\title{
UTAH STATE UNIVERSITY $\downarrow$ WATERSHED SCIENCES GRADUATE STUDENT INDUCTION COURSE
}

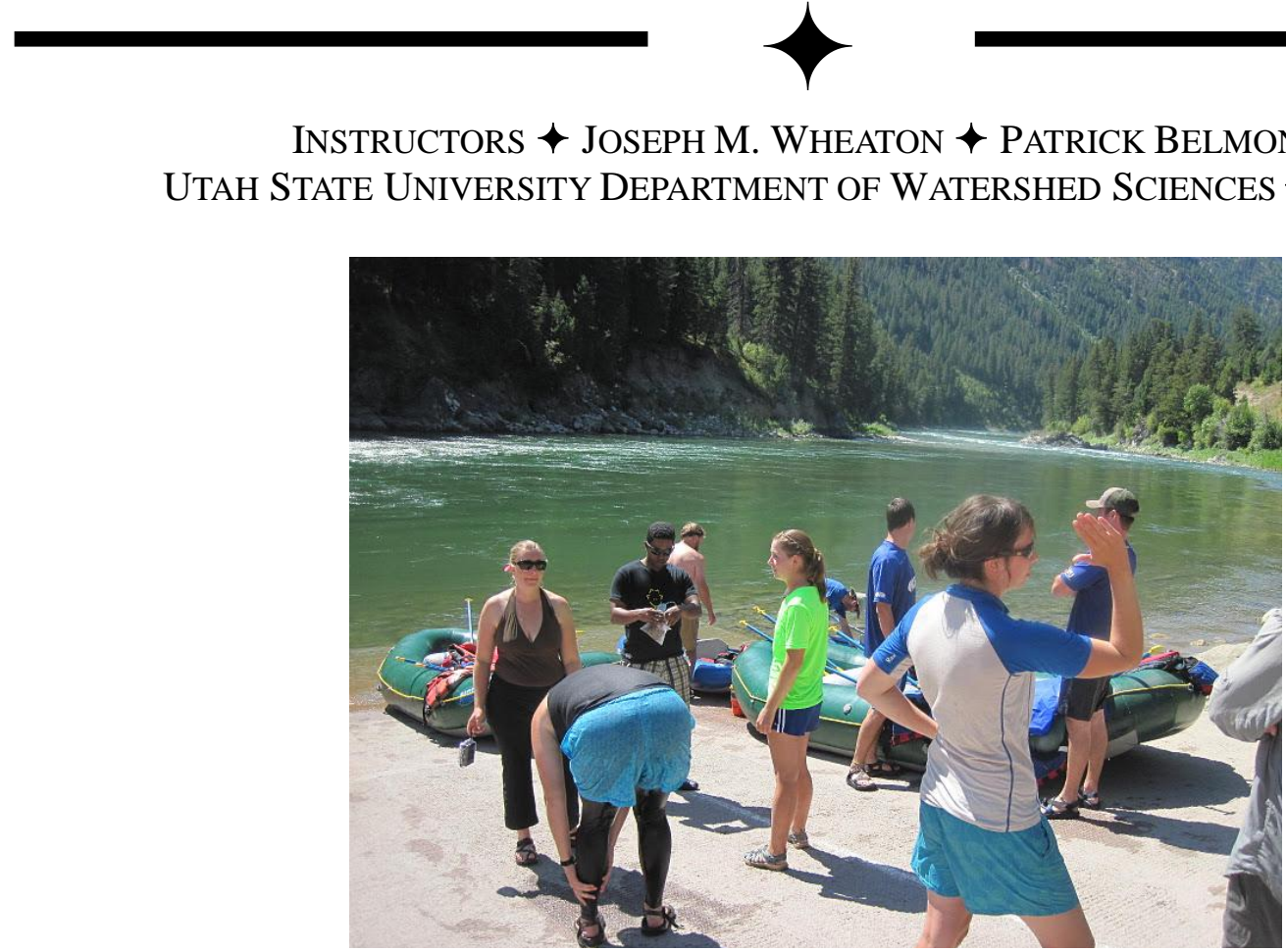

Figure 1. Students preparing to launch rafts on the Snake River.

\section{CLASS OVERVIEW}

Utah State University Department of Watershed Sciences runs an introductory course for all incoming graduate students (13 in Fall 2011) immediately prior to each Fall semester. The course is an intense, five day introduction to the fundamental concepts of Watershed Science, as well as the people of the Department of Watershed Science and the techniques they use in research. The course begins with one day focused on water quality and wetlands at Cutler Reservoir in Logan, Utah, then one and a half days focusing on collection of fish, remotely sensed data, and topographic surveys in the Logan River watershed, followed by one and a half days discussing landscape organization and evolution and making field observations in the Grand Teton region. We use AMK Ranch for lectures, discussions, group dinners, sleeping quarters, and as a central base for
Teton area activities, including rafting on the Snake River

\section{$\uparrow$ CLASS OBJECTIVES}

The general objectives of the course are to help incoming graduate students get acquainted with the nearby landscape, the people in the Department of Watershed Sciences, some of the broader concepts and questions that define Watershed Science, and some of the techniques that USU faculty use to answer those questions.

A sampling of the techniques demonstrated: Terrestrial laser scanning, Real-time kinematic GPS, Collection of visible in IR aerial photography using drone aircraft, Field mapping, Soil evaluation, Collection and analysis of climate data, Fish and macroinvertebrate sampling, Water quality monitoring 